\title{
Analysis of global Aeromonas veronii genomes provides novel information on source of infection and virulence in human gastrointestinal diseases
}

\author{
Fang Liu ${ }^{1 \dagger}$, Christopher Yuwono ${ }^{1 \dagger}$, Alfred Chin Yen Tay ${ }^{2}$, Michael C. Wehrhahn ${ }^{3}$, Stephen M. Riordan ${ }^{4}$ and \\ Li Zhang $^{1 *}$
}

\begin{abstract}
Background: Aeromonas veronii is a Gram-negative rod-shaped motile bacterium that inhabits mainly freshwater environments. A. veronii is a pathogen of aquatic animals, causing diseases in fish. A. veronii is also an emerging human enteric pathogen, causing mainly gastroenteritis with various severities and also often being detected in patients with inflammatory bowel disease. Currently, limited information is available on the genomic information of $A$. veronii strains that cause human gastrointestinal diseases.

Here we sequenced, assembled and analysed 25 genomes (one complete genome and $24 \mathrm{draft}$ genomes) of $A$. veronii strains isolated from patients with gastrointestinal diseases using combine sequencing technologies from Illumina and Oxford Nanopore. We also conducted comparative analysis of genomes of $168 \mathrm{global} A$. veronii strains isolated from different sources.

Results: We found that most of the A. veronii strains isolated from patients with gastrointestinal diseases were closely related to each other, and the remaining were closely related to strains from other sources. Nearly 300 putative virulence factors were identified. Aerolysin, microbial collagenase and multiple hemolysins were present in all strains isolated from patients with gastrointestinal diseases. Type III Secretory System (T3SS) in A. veronii was in AVI-1 genomic island identified in this study, most likely acquired via horizontal transfer from other Aeromonas species. T3SS was significantly less present in $A$. veronii strains isolated from patients with gastrointestinal diseases as compared to strains isolated from fish and domestic animals.
\end{abstract}

Conclusions: This study provides novel information on source of infection and virulence of $A$. veronii in human gastrointestinal diseases.

Keywords: Aeromonas, Aeromonas veronii, Genome, Gastroenteritis, Inflammatory bowel disease

*Correspondence: L.Zhang@unsw.edu.au

${ }^{\dagger}$ Fang Liu and Christopher Yuwono contributed equally to this work.

1 School of Biotechnology and Biomolecular Sciences, University of New

South Wales, Sydney, NSW 2052, Australia

Full list of author information is available at the end of the article

\section{Introduction}

Aeromonas veronii is a Gram-negative rod-shaped motile bacterium that inhabits mainly freshwater environments such as ground water, lakes and river [1]. It has also been isolated from chlorinated and untreated drinking water [2-6]. Several Aeromonas species including A. veronii are pathogens of aquatic animals, causing diseases such 
as skin ulceration and systemic hemorrhagic septicemia in fish, which is a great concern in aquaculture globally [7-9].

A. veronii and several other Aeromonas species also cause human diseases. The most common diseases caused by Aeromonas species in humans are gastroenteritis, soft-tissue infections and bacteremia [1]. Aeromonas species associated human gastroenteritis are mainly caused by three Aeromonas species including $A$. veronii, Aeromonas caviae and Aeromonas hydrophila, with $A$. veronii being the most commonly isolated species [10]. Aeromonas species caused human gastrointestinal infections are positively associated with increasing age [10]. Aeromonas species caused gastroenteritis may present with acute or chronic courses [11-15] While most patients can recover without medical treatment, those with severe symptoms and chronic infections often require hospital admission and antibiotic therapy [14]. In addition to gastroenteritis, Aeromonas species were often detected in patients with inflammatory bowel disease [16].

Several studies have examined the genomes of $A$. veronii strains isolated from dairy cattle, fish, and environmental samples [17, 18]. However, limited genomic data from $A$. veronii strains isolated from patients with gastrointestinal diseases are available. In order to better understand the pathogenicity of $A$. veronii in human diseases, there is a need to examine the genomes of $A$. veronii strains isolated from patients with gastrointestinal diseases.

In this study, we sequenced, assembled and analysed 25 genomes of $A$. veronii strains isolated from fecal samples of patients with gastrointestinal diseases, including one complete and 24 draft genomes. These $25 \mathrm{~A}$. veronii strains were identified in our previous study based on the sequences of seven housekeeping genes including $g y r \mathrm{~B}, r p o \mathrm{D}, g y r \mathrm{~A}, r e c \mathrm{~A}, d n a \mathrm{~J}, d n a \mathrm{X}$ and $a t p \mathrm{D}[10]$. Comparative genome analysis of $168 \mathrm{~A}$. veronii strains isolated from different sources in 18 countries were also conducted.

\section{Results}

The complete and draft genomes of $25 \mathrm{~A}$. veronii strains isolated from fecal samples of patients with gastroenteritis We successfully obtained the complete genome of $A$. veronii strain $\mathrm{A} 29 \mathrm{~V}$ through hybrid assembly of the data obtained from Illumina MiSeq sequencing and Oxford Nanopore sequencing. The complete genome of A. veronii strain $\mathrm{A} 29 \mathrm{~V}$ had a size of $4.54 \mathrm{Mb}$, with a GC content of $58.8 \%$. Two plasmids, designated as pAV1K and pAV7K, were identified in strain A29V, consisting of 1740 and 7073 bp respectively, with each encoding one and five proteins respectively. The PAV1K was found in another four $A$. veronii strains (pamvotica, NK02, CNRT12, and NK07), as well as other Aeromonas species including Aeromonas popoffii (strain CIP 105,493), Aeromonas sobria (strains 2014-10,509-27-20 and PAQ091014-19), and Aeromonas allosaccharophila (strain Z9-6), while pAV7K was only found in one additional $A$. veronii strain UDRT09. No potential virulence factors were identified in these two plasmids.

The detailed information of the $25 \mathrm{~A}$. veronii genomes sequenced in this study are shown in Table 1.

\section{Phylogenetic analysis of global $A$. veronii genomes}

A total of $168 \mathrm{~A}$. veronii genomes were used for analysis in this study, including $25 \mathrm{~A}$. veronii genomes sequenced in this study and $143 \mathrm{~A}$. veronii genomes obtained from public databases (Table 2). The $A$. veronii genomes in the public databases were obtained from National Center for Biotechnology Information (NCBI) genome database and their genome details and isolation sources were recorded. The core genome of the $168 \mathrm{~A}$. veronii strains contained 1315 genes. Based on the maximum likelihood phylogenetic tree constructed from the core genome of the $168 \mathrm{~A}$. veronii strains, three distinctive phylogenetic clusters were observed (Fig. 1). Cluster 1 contained 149 $A$. veronii strains (bootstrap value 99), which were from 18 countries. Cluster 2 (bootstrap value 100) had $11 \mathrm{~A}$. veronii strains, which were from five countries including Australia (four strains), China (four strains), Israel (one strain), India (one strain) and USA (one strain). Cluster 3 (bootstrap value 100) contained the remaining eight $A$. veronii strains, which were from seven countries including Australia (two strains), Turkey (one strain), South Africa (one strain), India (one strain), Germany (one strain), Spain (one strain) and China (one strain). All three clusters contained strains from different sources, including humans, animals and environmental samples (Fig. 1).

Within Cluster 1, $A$. veronii strains isolated from environmental samples or domestic animals from the same geographic locations often formed small groups (Fig. 1). For example, 13 of the $17 \mathrm{~A}$. veronii strains isolated from dairy cattle were in the same group (bootstrap value 100). The five strains isolated from pig rectal swabs from South Africa (A31, A5, A86, A34 and A136) were in the same group (bootstrap value 100). Similarly, the nine strains (PDB, NS2, NS6.15.2, NS22, NS13, NS, VCK1, AG5.28.6 and BIOO50A) isolated from Dicentrarchus labrax fish from Greece also formed their own group (bootstrap value 100) (Fig. 1).

The average nucleotide identity (ANI) values of each $A$. veronii strain against the other $167 \mathrm{~A}$. veronii strains were mostly over 95\%. An exception was strain WP2-S18CRE-03, which was isolated from a wastewater treatment 


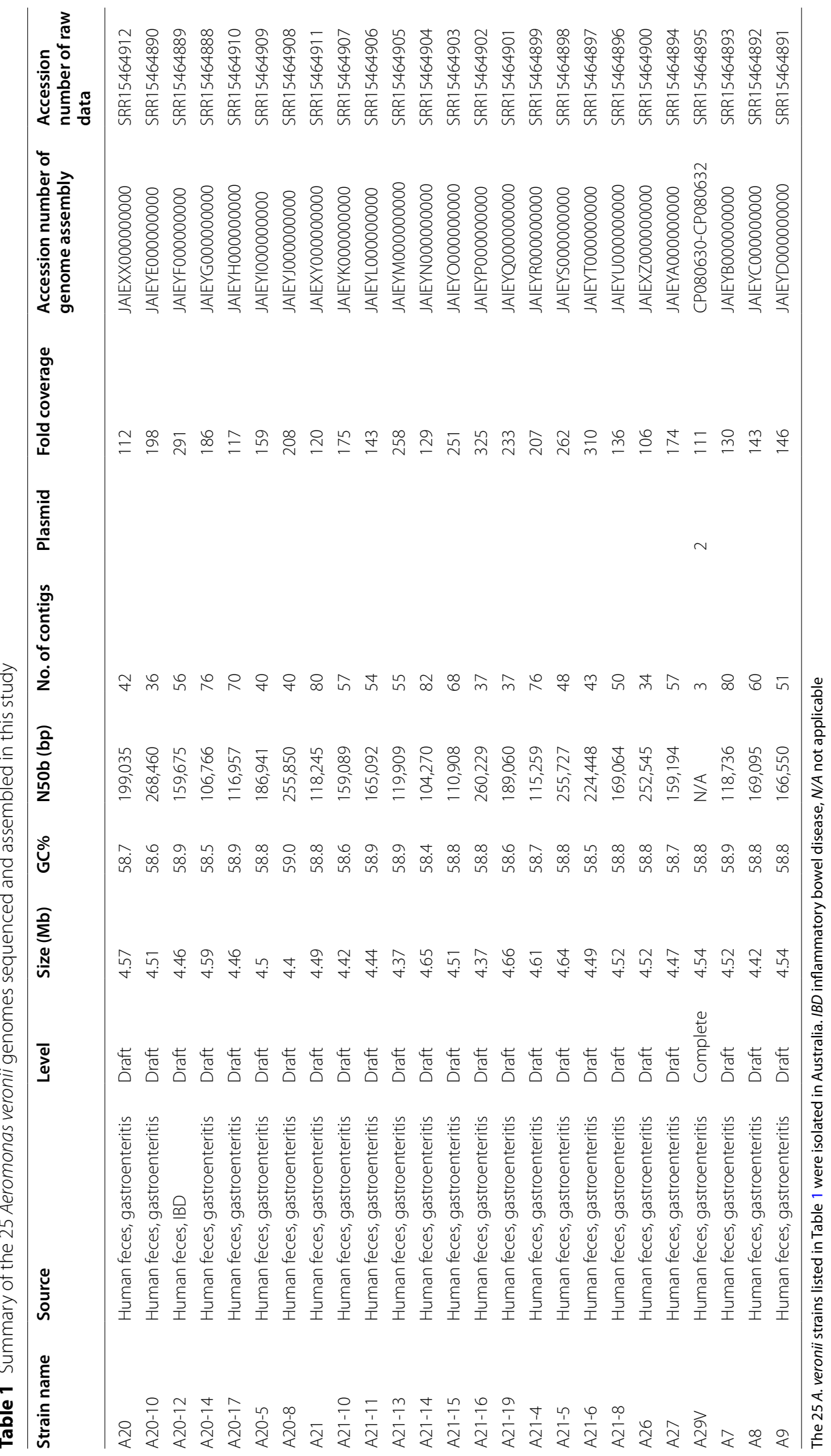


Table 2 The 143 Aeromonas veronii strains in the public databases that were used in this study

\begin{tabular}{|c|c|c|c|c|c|c|c|c|c|}
\hline Strain names & Country & Source & Level & Size (Mb) & $\begin{array}{l}\mathrm{GC} \\
\%\end{array}$ & N50 (bp) & No. of contigs & Plasmid & Ref \\
\hline BC88 & Australia & Human feces, dysentery & Draft & 4.60 & 58.5 & 215,763 & 155 & & \\
\hline FC951 & India & Human feces, diarrhea & Complete & 4.86 & 58.7 & N/A & 2 & 1 & \\
\hline $126-14$ & China & Human feces, diarrhea & Draft & 4.37 & 58.6 & 72,935 & 146 & & \\
\hline $312 \mathrm{M}$ & Brazil & Human feces, gastroenteritides & Draft & 4.57 & 58.6 & 502,756 & 14 & & \\
\hline VBF557 & India & Human feces, gastroenteritides & Draft & 4.70 & 58.4 & 19,666 & 526 & & \\
\hline ERR1305902-bin.15 & Denmark & Human feces, diarrhea & Draft & 4.11 & 59.4 & 32,267 & 226 & & \\
\hline CN17A0013 & China & Human feces & Draft & 4.45 & 58.9 & 167,760 & 49 & & \\
\hline CN17A0029 & China & Human feces & Draft & 4.60 & 58.8 & $2,737,631$ & 19 & & \\
\hline CN17A0031 & China & Human feces & Draft & 4.42 & 58.9 & 156,076 & 45 & & \\
\hline CN17A0036 & China & Human feces & Draft & 4.45 & 58.9 & 230,866 & 38 & & \\
\hline CN17A0040 & China & Human feces & Draft & 4.44 & 58.9 & 302,838 & 32 & & \\
\hline CN17A0049 & China & Human feces & Draft & 4.30 & 58.9 & 302,677 & 31 & & \\
\hline CN17A0054 & China & Human feces & Draft & 4.33 & 58.9 & 217,304 & 57 & & \\
\hline CN17A0059 & China & Human feces & Draft & 4.26 & 58.9 & 164,457 & 48 & & \\
\hline CN17A0067 & China & Human feces & Draft & 4.55 & 58.7 & 180,288 & 60 & & \\
\hline CN17A0087 & China & Human feces & Draft & 4.58 & 58.6 & 145,832 & 80 & & \\
\hline CN17A0093 & China & Human feces & Draft & 4.35 & 58.6 & 120,695 & 64 & & \\
\hline CN17A0097 & China & Human feces & Draft & 4.52 & 58.6 & 141,638 & 88 & & \\
\hline CN17A0102 & China & Human feces & Draft & 4.47 & 58.7 & 126,005 & 75 & & \\
\hline CN17A0103 & China & Human feces & Draft & 4.43 & 58.8 & 110,083 & 102 & & \\
\hline CN17A0114 & China & Human feces & Draft & 4.43 & 58.9 & 237,189 & 35 & & \\
\hline CN17A0120 & China & Human feces & Draft & 4.52 & 58.6 & 82,803 & 128 & & \\
\hline CN17A0122 & China & Human feces & Draft & 4.48 & 58.7 & 196,730 & 33 & & \\
\hline CN17A0154 & China & Human feces & Draft & 4.44 & 59.0 & 260,206 & 33 & & \\
\hline ADV102 & France & Human feces & Draft & 4.52 & 58.6 & 108,450 & 87 & & [19] \\
\hline AMC34 & USA & Human intestinal tract & Draft & 4.58 & 58.4 & 219,183 & 1 & & \\
\hline MGYG-HGUT-02529 & China & Human gut & Draft & 4.70 & 58.4 & 119,499 & 124 & & \\
\hline ZJ12-3 & China & Human rectal swab & Draft & 4.70 & 58.4 & 119,499 & 124 & & \\
\hline $\begin{array}{l}\text { AVNIH1 } \\
\text { (GCA_001634325) }\end{array}$ & USA & Human perirectal swab & Complete & 4.96 & 58.5 & N/A & 2 & 1 & [20] \\
\hline AVNIH2 & USA & Human perirectal swab & Draft & 4.52 & 58.9 & 211,774 & 50 & & [20] \\
\hline $1708-29,120$ & China & Human cholangiolithiasis bile & Complete & 4.50 & 58.9 & N/A & 1 & & \\
\hline C198 & Thailand & Human blood, septicaemia & Draft & 4.58 & 58.6 & $4,550,752$ & 3 & & \\
\hline FDAARGOS_632 & USA & Human & Complete & 4.56 & 58.9 & N/A & 2 & 1 & \\
\hline CECT 4257 & USA & Human sputum & Draft & 4.52 & 58.9 & 148,348 & 52 & & {$[21]$} \\
\hline AER39 & USA & Human blood & Draft & 4.42 & 58.8 & 188,051 & 4 & & [21] \\
\hline AER397 & USA & Human blood & Draft & 4.50 & 58.8 & 645,709 & 5 & & {$[21]$} \\
\hline BVH37 & France & Human blood & Draft & 4.46 & 58.8 & 115,181 & 55 & & [19] \\
\hline BVH46 & France & Human blood & Draft & 4.51 & 58.8 & 215,038 & 39 & & {$[22]$} \\
\hline $\mathrm{BVH} 47$ & France & Human blood & Draft & 4.64 & 58.9 & 96,732 & 108 & & [19] \\
\hline AK247 & France & Human forehead abscess & Draft & 4.55 & 58.8 & 260,691 & 36 & & [19] \\
\hline AMC35 & USA & Human wound & Draft & 4.57 & 58.5 & 351,392 & 2 & & {$[21]$} \\
\hline CCM 4359 & USA & Human sputum, drowning & Draft & 4.51 & 58.9 & 245,067 & 56 & & \\
\hline TTU2014-108AME & USA & Dairy cattle feces & Draft & 4.53 & 58.7 & 162,342 & 62 & & [17] \\
\hline TTU2014-108ASC & USA & Dairy cattle feces & Draft & 4.53 & 58.7 & 187,473 & 58 & & {$[17]$} \\
\hline TTU2014-113AME & USA & Dairy cattle feces & Draft & 4.66 & 58.6 & 74,547 & 122 & & [17] \\
\hline TTU2014-115AME & USA & Dairy cattle feces & Draft & 4.53 & 58.7 & 205,013 & 53 & & {$[17]$} \\
\hline TTU2014-115ASC & USA & Dairy cattle feces & Draft & 4.53 & 58.7 & 233,487 & 52 & & {$[17]$} \\
\hline TTU2014-125ASC & USA & Dairy cattle feces & Draft & 4.68 & 58.6 & 168,256 & 58 & & [17] \\
\hline
\end{tabular}


Table 2 (continued)

\begin{tabular}{|c|c|c|c|c|c|c|c|c|c|}
\hline Strain names & Country & Source & Level & Size (Mb) & $\begin{array}{l}\text { GC } \\
\%\end{array}$ & N50 (bp) & No. of contigs & Plasmid & Ref \\
\hline TTU2014-130AME & USA & Dairy cattle feces & Draft & 4.68 & 58.6 & 189,668 & 64 & & [17] \\
\hline TTU2014-130ASC & USA & Dairy cattle feces & Draft & 4.68 & 58.6 & 247,513 & 49 & & [17] \\
\hline TTU2014-131ASC & USA & Dairy cattle feces & Draft & 4.68 & 58.6 & 187,444 & 70 & & [17] \\
\hline TTU2014-134AME & USA & Dairy cattle feces & Draft & 4.68 & 58.6 & 204,478 & 50 & & [17] \\
\hline TTU2014-134ASC & USA & Dairy cattle feces & Draft & 4.68 & 58.6 & 193,661 & 59 & & [17] \\
\hline TTU2014-140ASC & USA & Dairy cattle feces & Draft & 4.68 & 58.6 & 148,012 & 81 & & [17] \\
\hline TTU2014-141AME & USA & Dairy cattle feces & Draft & 4.68 & 58.6 & 223,907 & 48 & & [17] \\
\hline TTU2014-141ASC & USA & Dairy cattle feces & Draft & 4.68 & 58.6 & 241,272 & 45 & & [17] \\
\hline TTU2014-142ASC & USA & Dairy cattle feces & Draft & 4.68 & 58.6 & 247,560 & 45 & & [17] \\
\hline TTU2014-143AME & USA & Dairy cattle feces & Draft & 4.68 & 58.6 & 204,478 & 59 & & [17] \\
\hline TTU2014-143ASC & USA & Dairy cattle feces & Draft & 4.68 & 58.6 & 202,296 & 54 & & [17] \\
\hline $\mathrm{A} 31$ & South Africa & Pig rectal swab & Draft & 4.64 & 58.5 & 114,767 & 84 & & \\
\hline A5 & South Africa & Pig rectal swab & Draft & 4.77 & 58.2 & 230,041 & 33 & & \\
\hline A86 & South Africa & Pig rectal swab & Draft & 4.64 & 58.5 & 206,004 & 42 & & \\
\hline A34 & South Africa & Pig rectal swab & Draft & 4.64 & 58.5 & 139,859 & 82 & & \\
\hline A136 & South Africa & Pig rectal swab & Draft & 4.67 & 58.4 & 213,730 & 41 & & \\
\hline Ae52 & Sri Lanka & Carassius auratus & Draft & 4.56 & 58.7 & 158,595 & 80 & & \\
\hline CL8155 & China & Carp gut, healthy & Draft & 4.68 & 58.6 & 284,020 & 50 & & \\
\hline$J C 529$ & China & Carp sepsis & Complete & 4.83 & 58.3 & N/A & 1 & & \\
\hline MS 17-88 & USA & Catfish & Draft & 5.18 & 58.2 & $1,334,815$ & 13 & & \\
\hline MS-18-37 & USA & Catfish & Complete & 4.68 & 58.6 & N/A & 1 & & \\
\hline ML09-123 & USA & Catfish & Draft & 4.75 & 58.4 & 299,782 & 32 & & \\
\hline VCK_1 & Greece & Dicentrarchus labrax kidney, diseased & Draft & 4.63 & 58.6 & 68,239 & 120 & & \\
\hline PDB & Greece & Dicentrarchus labrax kidney, diseased & Draft & 4.72 & 58.5 & 72,590 & 141 & & \\
\hline AG_5.28.6 & Greece & Dicentrarchus labrax kidney, diseased & Draft & 4.61 & 58.6 & 85,872 & 98 & & \\
\hline NS & Greece & Dicentrarchus labrax kidney, diseased & Draft & 4.71 & 58.5 & 67,042 & 140 & & \\
\hline NS2 & Greece & Dicentrarchus labrax kidney, diseased & Draft & 4.72 & 58.5 & 69,902 & 143 & & \\
\hline NS_6.15.2 & Greece & Dicentrarchus labrax kidney, diseased & Draft & 4.72 & 58.5 & 66,300 & 149 & & \\
\hline NS22 & Greece & Dicentrarchus labrax kidney, diseased & Draft & 4.74 & 58.4 & 61,224 & 172 & & \\
\hline NS13 & Greece & Dicentrarchus labrax kidney, diseased & Draft & 4.67 & 58.6 & 72,418 & 139 & & \\
\hline $\mathrm{BIOO50A}$ & Turkey & Dicentrarchus labrax kidney, diseased & Draft & 4.61 & 58.6 & 73,700 & 109 & & \\
\hline $17 \mathrm{ISAe}$ & South Korea & Discus spleen & Complete & 4.66 & 58.5 & N/A & 2 & 1 & \\
\hline A8-AHP & India & Labeo rohita, diseased & Complete & 4.77 & 58.4 & N/A & 4 & 3 & \\
\hline UBA1835 & Spain & Anguilla anguilla epidermal mucus & Draft & 4.11 & 59.0 & 17,609 & 323 & & \\
\hline ZfB1 & China & Fish & Complete & 4.71 & 58.5 & N/A & 1 & & \\
\hline Phln2 & India & Fish intestinal & Draft & 4.30 & 58.8 & 3789 & 1899 & & [21] \\
\hline CB51 & China & Grass carp & Complete & 4.58 & 58.6 & N/A & 1 & & [17] \\
\hline XH.VA.1 & China & Ictalurus punctatus & Draft & 5.36 & 56.5 & 259,638 & 62 & & \\
\hline XH.VA.2 & China & Ictalurus punctatus & Draft & 4.91 & 58.1 & 259,509 & 48 & & \\
\hline $\mathrm{x} 11$ & China & Megalobrama amblycephala & Complete & 4.28 & 58.8 & N/A & 1 & & \\
\hline $\mathrm{x} 12$ & China & Megalobrama amblycephala & Complete & 4.77 & 58.3 & N/A & 1 & & \\
\hline Aer_WatCTCBM21 & Brazil & Oreochromis niloticus & Draft & 4.60 & 58.7 & 317,324 & 45 & & \\
\hline CNRT12 & Thailand & Oreochromis sp. & Draft & 4.90 & 58.1 & 265,081 & 479 & & \\
\hline NK01 & Thailand & Oreochromis sp. & Draft & 4.56 & 58.5 & 171,547 & 95 & & \\
\hline NK02 & Thailand & Oreochromis sp. & Draft & 4.80 & 58.2 & 110,255 & 400 & & \\
\hline NK07 & Thailand & Oreochromis sp. & Draft & 4.78 & 58.6 & 214,996 & 46 & & \\
\hline UDRT09 & Thailand & Oreochromis sp. & Draft & 4.61 & 58.5 & 169,295 & 186 & & \\
\hline BAQ071013-135 & USA & Perch head kidney & Draft & 4.62 & 58.9 & 167,400 & 50 & & \\
\hline B44 & Brazil & Pseudoplatystoma corruscans kidney & Draft & 4.61 & 58.6 & 290,712 & 51 & & \\
\hline
\end{tabular}


Table 2 (continued)

\begin{tabular}{|c|c|c|c|c|c|c|c|c|c|}
\hline Strain names & Country & Source & Level & Size (Mb) & $\begin{array}{l}\mathrm{GC} \\
\%\end{array}$ & N50 (bp) & No. of contigs & Plasmid & Ref \\
\hline B48 & Brazil & Pseudoplatystoma corruscans kidney & Draft & 4.73 & 58.7 & 284,404 & 49 & & \\
\hline WB12 & China & Carassius auratus intestine, sick & Draft & 4.52 & 58.8 & 282,522 & 40 & & \\
\hline $\begin{array}{l}\text { AVNIH1 } \\
\text { (GCA_009834065) }\end{array}$ & South Korea & Silurus asotus & Complete & 4.81 & 58.5 & N/A & 1 & & \\
\hline TH0426 & China & Tachysurus fulvidraco & Complete & 4.92 & 58.3 & N/A & 1 & & \\
\hline $\mathrm{XU1}$ & Greece & Xiphophorus helleri kidney & Draft & 4.80 & 58.0 & 206,195 & 92 & & \\
\hline XhG1.2 & India & Xiphophorus hellerii & Draft & 4.57 & 58.7 & 305,294 & 34 & & \\
\hline HX3 & China & Alligator & Complete & 4.76 & 58.5 & N/A & 2 & 1 & \\
\hline CQ-AV1 & China & Andrias davidianus liver & Draft & 4.78 & 58.5 & 204,972 & 36 & & \\
\hline 161 & China & Channa argus & Draft & 4.51 & 58.7 & 312,206 & 28 & & \\
\hline LMG 13,067 & USA & Frog & Draft & 4.74 & 58.4 & 91,946 & 72 & & {$[21]$} \\
\hline S00030 & USA & Heterelmis comalensis & Draft & 4.51 & 58.7 & 237,167 & 21 & & \\
\hline $\mathrm{Hm} 21$ & Turkey & Hirudo verbena digestive tract & Complete & 4.77 & 58.7 & N/A & 2 & 1 & [21] \\
\hline CMF & India & Insect gut & Draft & 4.56 & 58.7 & 40,276 & 200 & & \\
\hline CIP 107,763 & India & Mosquito gut & Draft & 4.43 & 58.8 & 188,049 & 64 & & {$[21]$} \\
\hline AK241 & France & Snail & Draft & 4.60 & 58.6 & 215,278 & 42 & & [19] \\
\hline B565 & China & Aquaculture pond sediment & Complete & 4.55 & 58.7 & N/A & 1 & & [18] \\
\hline 22 & Brazil & Combined sewer & Draft & 5.09 & 58.3 & 66,851 & 185 & & \\
\hline 28 & Brazil & Combined sewer & Draft & 4.97 & 58.5 & 94,322 & 108 & & \\
\hline CECT 7059 & Spain & Drinking water & Draft & 4.81 & 58.4 & 188,889 & 31 & & \\
\hline RU31B & USA & Duckweeds & Draft & 4.53 & 58.7 & 73,776 & 93 & & \\
\hline СЕCT 4902 & Germany & Environment & Draft & 4.64 & 58.4 & 347,677 & 29 & & [19] \\
\hline AK236 & France & Lake water & Draft & 4.41 & 58.8 & 412,126 & 26 & & \\
\hline Colony604 & Thailand & Food & Draft & 4.57 & 57.8 & 7493 & 1 & & \\
\hline Colony 111 & Thailand & Food & Draft & 4.58 & 57.8 & 7510 & 1 & & \\
\hline Colony512 & Thailand & Food & Draft & 4.60 & 58.5 & 16,905 & 1 & & \\
\hline Colony 125 & Thailand & Food & Draft & 4.58 & 58.0 & 7702 & 1 & & \\
\hline pamvotica & Greece & Lake Pamvotis surface sentiment & Draft & 4.92 & 58.1 & 739,151 & 21 & & \\
\hline A134 & Israel & Lake Kinneret microcystis bloom & Draft & 4.41 & 58.7 & 50,812 & 151 & & \\
\hline S50-1 & USA & Organic kale & Draft & 4.56 & 58.5 & 104,479 & 130 & & \\
\hline CTe-01 & Peru & Oxidation pond & Draft & 4.68 & 58.6 & 111,555 & 200 & & \\
\hline ARB3 & Japan & Pond water & Draft & 4.54 & 58.8 & 205,115 & 63 & & {$[21]$} \\
\hline Z2-7 & China & Pork & Draft & 4.41 & 58.7 & 265,145 & 48 & & \\
\hline KLG7 & UK & River Don & Draft & 4.55 & 58.8 & 139,212 & 104 & & \\
\hline KLG5 & UK & River Don & Draft & 4.74 & 58.5 & 280,270 & 103 & & \\
\hline KLG8 & UK & River Don & Draft & 4.59 & 58.6 & 198,583 & 76 & & \\
\hline KLG9 & UK & River Don & Draft & 4.61 & 58.7 & 180,084 & 74 & & \\
\hline СЕCТ 4486 & Germany & Surface water & Draft & 4.41 & 58.9 & 90,706 & 66 & & [21] \\
\hline CCM 7244 & Germany & Surface water & Draft & 4.42 & 58.9 & 185,495 & 74 & & [17] \\
\hline A29 & South Africa & Surface water & Draft & 4.48 & 58.8 & 165,894 & 54 & & \\
\hline AK227 & France & Wastewater treatment plant & Draft & 4.40 & 58.7 & 105,208 & 67 & & \\
\hline WP2-S18-CRE-03 & Japan & Wastewater treatment plant & Complete & 4.94 & 58.6 & N/A & 4 & 3 & \\
\hline WP3-W19-ESBL-03 & Japan & Wastewater treatment plant & Complete & 4.98 & 58.7 & N/A & 6 & 4 & \\
\hline WP8-S18-ESBL-11 & Japan & Wastewater treatment plant & Complete & 4.91 & 58.7 & N/A & 4 & 3 & \\
\hline WP8-W19-CRE-03 & Japan & Wastewater treatment plant & Complete & 4.79 & 58.5 & N/A & 6 & 4 & \\
\hline WP9-W18-ESBL-04 & Japan & Wastewater treatment plant & Complete & 4.93 & 58.7 & $\mathrm{~N} / \mathrm{A}$ & 5 & 4 & \\
\hline D & South Africa & Water & Draft & 4.43 & 59.0 & 54,053 & 149 & & \\
\hline
\end{tabular}


plant in Japan. This strain had ANI values 91- 92\% against the other 167 A. veroniis strains.

\section{Strains closely related to $A$. veronii strains isolated from fecal samples of patients with gastrointestinal diseases}

Strains that are closed related to the $31 \mathrm{~A}$. veronii strains isolated from patients with gastrointestinal diseases were identified based on the highest ANI values. Twenty-two (71\%, 22/31) closely related $A$. veronii strains were from fecal samples of other human individuals, 19 of these 22 individuals had recorded gastrointestinal diseases. Nine closely related $A$. veronii strains $(29 \%, 9 / 31)$ were from freshwater fish or domestic animals (cattle and pig) (Table 3). Of the $26 \mathrm{~A}$. veronii strains isolated from patients with gastrointestinal diseases in Australia, 16 strains $(61.5 \%, 15 / 26)$ had closely related strains from patients in Australia, four strains $(15.4 \%, 4 / 26)$ had closely related strains isolated from intestinal tract of individuals in other countries (one patient had gastroenteritis and the clinical conditions of the remaining three individuals were not known), the remaining six A. veronii strains (23\%) had closely related strains from various sources including freshwater fish, domestic animals, leech and surface water (Table 3).

\section{Secretion systems}

Secretion systems in the genomes of $168 \mathrm{~A}$. veronii strains were examined. Five types of secretion systems, including Type I Secretion System (T1SS), T2SS, T3SS, T4SS and T6SS were identified in A. veronii (Additional file 1).

T1SS system was found in all $A$. veronii strains except strain ERR1305902-bin.15. T2SS secretion system was found in all $168 \mathrm{~A}$. veronii strains.

T3SS was found in 106 of the $168 \mathrm{~A}$. veronii strains (63.1\%). A. veronii strains isolated from freshwater fish, environmental samples, domestic animals (cattle and pigs) and other animals had T3SS positivity of $84 \%$ (32/38), 60\% (15/25), 100\% (22/22) and 70\% (7/10) respectively. The 'other animals' group included $A$. veronii strains isolated from mosquito gut, insect gut, hirudo verbena digestive tract, grass carp, Heterelmis comalensis, Xiphophorus helleri, frog, snail, Andrias advidianus and alligator.

The T3SS positivity in A. veronii strains isolated from patients with gastrointestinal diseases, bacteremia and other human samples was 48\% (15/32), 83\% (5/6) and $30 \%(9 / 30)$ respectively. The 'other human sample' group included $A$. veronii strains isolated from sputum, wound infection, bile of gallstone and fecal samples of individuals without clinical information. The T3SS positivity in $A$. veronii strains isolated from patients with gastrointestinal diseases was significantly lower than that in $A$. veronii strains isolated from freshwater fish $(p=0.002)$ and domestic animals $(p<0.0001)$. The other statistical analysis data are shown in Fig. 2A. The negativity of T3SS was confirmed by searching the franking genes in the T3SS negative strains.

A number of T4SS components were found in several $A$. veronii strains, mainly strains isolated from dairy cattle in USA. T6SS was found in 55 of the 168 A. veronii strains examined (32.7\%) and it did not show a statistical significance in strains isolated from different sources (Additional file 1).

\section{T3SS in A. veronii is located in a genomic island} that is highly similar to plasmids in Aeromonas salmonicida Comparison of the genomes of 23 complete $A$. veronii genomes (11 T3SS positive and 12 T3SS negative) revealed that T3SS in $A$. veronii is located on a genomic island, which we named $A$. veronii genomic island-1 (AVI-1) (Fig. 2B). AVI-1 genomic island has a size of 26,064 bp and GC content of $60 \%$. The AVI-1 island is adjunct to a gene encoding crossover junction endodeoxyribonuclease, an enzyme involving in homologous recombination. The components of $A$. veronii T3SS were shown in Fig. 2C.

Blast search against all bacterial genomes in public databases showed that the AVI-1 genomic island was also found in some A. hydrophilia and Aeromonas salmonicida strains. For example, the AVI-1 island is in the chromosome of $A$. hydrophila strains 23-C-23 and WCX23 (97\% query coverage and $95.57 \%$ identity). In A. salmonicida, the AVI-1 island is in plasmids, for example plasmid pS44-3 in strain S44 and plasmid pS121-3 in strain S121 (97\% query coverage and $94.85 \%$ identity).

\section{Virulence factors}

Two hundred and ninety-nine putative virulence factors were identified in the complete genome of $A$. veronii strain A29V, including molecules involved in adherence, colonization, invasion, secretion systems, mobility, immune evasion, antiphagocytosis and others (Fig. 3).

(See figure on next page.)

Fig. 1 Phylogenetic tree generated based on Aeromonas veronii core genome. The phylogenetic tree was generated based on the core genome of 168 A. veronii strains isolated from different sources globally using maximum likelihood method by FastTree. The 168 A. veronii strains formed three clusters. Cluster 1 (shaded light grey colour, bootstrap value 99) contained 149 A. veronii strains, Cluster 2 (shaded yellow colour, bootstrap value 100) contained 11 strains and Cluster 3 (shaded pink colour, bootstrap value 100) contained eight strains. Within Cluster 1 , strains isolated from the same environmental or animal sources often formed small groups. The genomes of $A$. veronii strains with blue colour were sequenced in this study 


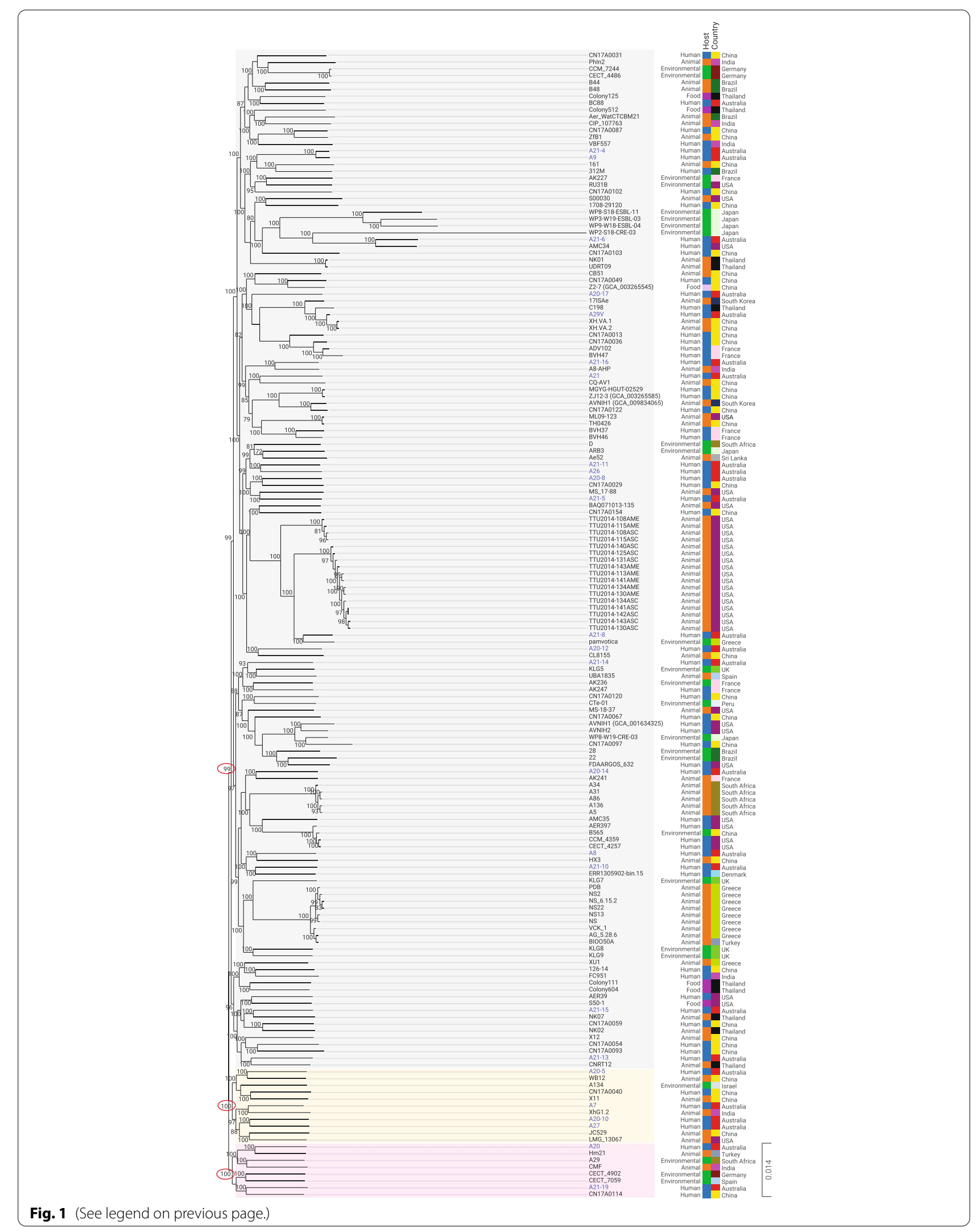


Table 3 Strains that are most closely related to the 31 Aeromonas veronii strains isolated from patients with gastrointestinal diseases

\begin{tabular}{|c|c|}
\hline $\begin{array}{l}\text { A. veronii strains isolated from fecal samples } \\
\text { of patients with gastrointestinal diseases }\end{array}$ & $\begin{array}{l}\text { Most closely related } \\
\text { strain (ANI value) }\end{array}$ \\
\hline${ }^{\mathrm{a}} \mathrm{A} 20$ & Hm21(97.09) \\
\hline${ }^{\mathrm{a}} \mathrm{A} 20-10$ & ${ }^{\mathrm{a}} \mathrm{A} 7$ (96.769) \\
\hline${ }^{\mathrm{a}} \mathrm{A} 20-12$ & ${ }^{\mathrm{a} A 21-8}(96.74)$ \\
\hline${ }^{\mathrm{a}} \mathrm{A} 21-14$ & ${ }^{c}$ CECT 4257 (96.7) \\
\hline${ }^{\mathrm{a} A 20}-17$ & ${ }^{\mathrm{a} A 21-13(96.55)}$ \\
\hline${ }^{\mathrm{a}} \mathrm{A} 20-5$ & ${ }^{\mathrm{a}} \mathrm{A} 7(96.79)$ \\
\hline${ }^{\mathrm{a} A 20-8}$ & ${ }^{c} \mathrm{CN} 17 \mathrm{A0029}$ (96.84) \\
\hline${ }^{\mathrm{a}} \mathrm{A} 21$ & ${ }^{\mathrm{a} A 21-5}(96.58)$ \\
\hline${ }^{\mathrm{a}} \mathrm{A} 21-10$ & A29 (96.60) \\
\hline${ }^{\mathrm{a}} \mathrm{A} 21-11$ & ${ }^{\mathrm{a}} \mathrm{A} 21-5$ (96.7) \\
\hline${ }^{\mathrm{a}} \mathrm{A} 21-13$ & ${ }^{\mathrm{a}} \mathrm{A} 21-15$ (96.66) \\
\hline${ }^{\mathrm{a}} \mathrm{A} 21-14$ & ${ }^{c}$ CECT 4257 (96.7) \\
\hline${ }^{\mathrm{a} A 21-15}$ & ${ }^{\mathrm{a}} \mathrm{A} 21-13(96.58)$ \\
\hline${ }^{\mathrm{a} A 21-16}$ & A8-AHP (97.5) \\
\hline${ }^{\mathrm{a}} \mathrm{A} 21-19$ & A136 (96.69) \\
\hline${ }^{\mathrm{a}} \mathrm{A} 21-4$ & ${ }^{\mathrm{a}} \mathrm{A9}(99.30)$ \\
\hline${ }^{\mathrm{a}} \mathrm{A} 21-5$ & ${ }^{\mathrm{a}} \mathrm{A} 21-11(96.7)$ \\
\hline${ }^{\mathrm{a} A 21-6}$ & ${ }^{C} A M C 34$ (97.85) \\
\hline aA21-8 & TTU2014-130AME (98.1) \\
\hline${ }^{\mathrm{a}} \mathrm{A} 26$ & ${ }^{\mathrm{a}} \mathrm{A} 21-11(96.64)$ \\
\hline${ }^{\mathrm{a}} \mathrm{A} 27$ & ${ }^{\mathrm{a} A 7}(96.72)$ \\
\hline${ }^{\mathrm{a}} \mathrm{A} 29 \mathrm{~V}$ & XH.VA.2 (99.48) \\
\hline${ }^{\mathrm{a}} \mathrm{A} 7$ & ${ }^{\mathrm{a}} \mathrm{A} 20-5$ (96.81) \\
\hline${ }^{\mathrm{a} A 7}$ & ${ }^{\mathrm{a} A 20-5}(96.81)$ \\
\hline${ }^{\mathrm{a}} \mathrm{A} 9$ & ${ }^{\mathrm{a}} \mathrm{A} 21-4$ (99.25) \\
\hline${ }^{\mathrm{a}} \mathrm{BC} 88$ & ${ }^{\mathrm{a}} \mathrm{A} 20-10$ (96.56) \\
\hline${ }^{b} \mathrm{FC} 951$ & XU1 (96.55) \\
\hline${ }^{b} 121-14$ & XU1 (96.71) \\
\hline$b_{312 M}$ & $161(97.16)$ \\
\hline bVBF557 & ${ }^{\mathrm{a}} \mathrm{A} 21-8(96.41)$ \\
\hline bERR1305902-bin.15 & ${ }^{\mathrm{a}} \mathrm{A} 8(96.84)$ \\
\hline
\end{tabular}

${ }^{a}$ A. veronii strains isolated from feces of patients with gastrointestinal diseases in Australia

${ }^{\mathrm{b}}$ strains isolated from diarrheal feces of patients from other countries

c strains isolated from feces of human individuals without clear clinical information

Toxins produced by the $31 \mathrm{~A}$. veronii strains isolated from patients with gastrointestinal diseases were further examined. Two secreted toxins, aerolysin and microbial collagenase, were found in all 31 strains (Fig. 4). The aerolysin proteins in different $A$. veronii strains were highly similar, with the overall protein sequence identity being $75 \%$ among the 31 strains (Additional file 2). The protein sequences of aerolysin in $A$. hydrophila showed some variations, the sequence identity between $A$. veronii aerolysin and $A$. hydrophila aerolysin varied between 69 and
98\%. Shiga toxin 1 (Stx1) and Shiga toxin 2 (Stx2) were not found in any of these strains. Zonula occludens toxin (Zot) was found in 11 of the 31 strains (35.5\%). The Zot proteins in A. veronii and Vibrio cholerae shared $36 \%$ of protein sequence identity.

\section{Discussion}

In this study, we sequenced and assembled 25 genomes of $A$. veronii strains isolated from fecal samples of patients with gastrointestinal infections in Australia and conducted comparative genome analysis of 168 global $A$. veronii strains, including the $25 \mathrm{~A}$. veronii genomes that we have sequenced and additional $143 A$. veronii strains isolated from different sources in 18 countries in Asia, Europe, Africa, Oceania, North and South America.

Twenty-five genomes, including one complete genome and 24 draft genomes of $A$. veronii strains isolated from patients with gastrointestinal diseases were successfully obtained in this study (Table 1). Despite the increasing importance of $A$. veronii in causing human gastrointestinal diseases, only six genomes of $A$. veronii strains isolated from patients with gastrointestinal diseases were available in public databases prior to this study. Our 25 $A$. veronii genomes will provide a useful source for future research on $A$. veronii.

Global A. veronii strains including 168 strains from 18 countries were used for phylogenetic analysis (Table 2). These 168 A. veronii strains formed three phylogenetic clusters based on the core genome (Fig. 1). Each cluster had $A$. veronii strains from different sources, showing the ancestors of these three clusters were not determined by the isolation sites. Most of the A. veronii strains (88.7\%) from various sources in different countries were in Cluster 1 , showing that the majority of $A$. veronii strains globally were derived from a common ancestor. Strains isolated from the same environmental or animal sources often formed small groups within Cluster 1, most likely reflecting variations in $A$. veronii isolates obtained from a single site.

The majority of the $31 \mathrm{~A}$. veronii strains $(71 \%)$ isolated from fecal samples of patients with gastrointestinal diseases were closely related to strains isolated from fecal samples of the other human individuals, most of whom had gastrointestinal diseases (Table 3). Only 29\% of $A$. veronii strains isolated from fecal samples of patients with gastrointestinal diseases were closely related to strains isolated from freshwater fish and domestic animals. This interesting finding suggests that the main source for human gastrointestinal infections of $A$. veronii was not from freshwater fish or domestic animals, although they can serve as potential sources of infection. In addition to freshwater fish, domestic animals and environmental samples, $A$. veronii has also been frequently isolated from 


\section{A}

Prevalence of T3SS in Aeromonas veronii strains isolated from different sources

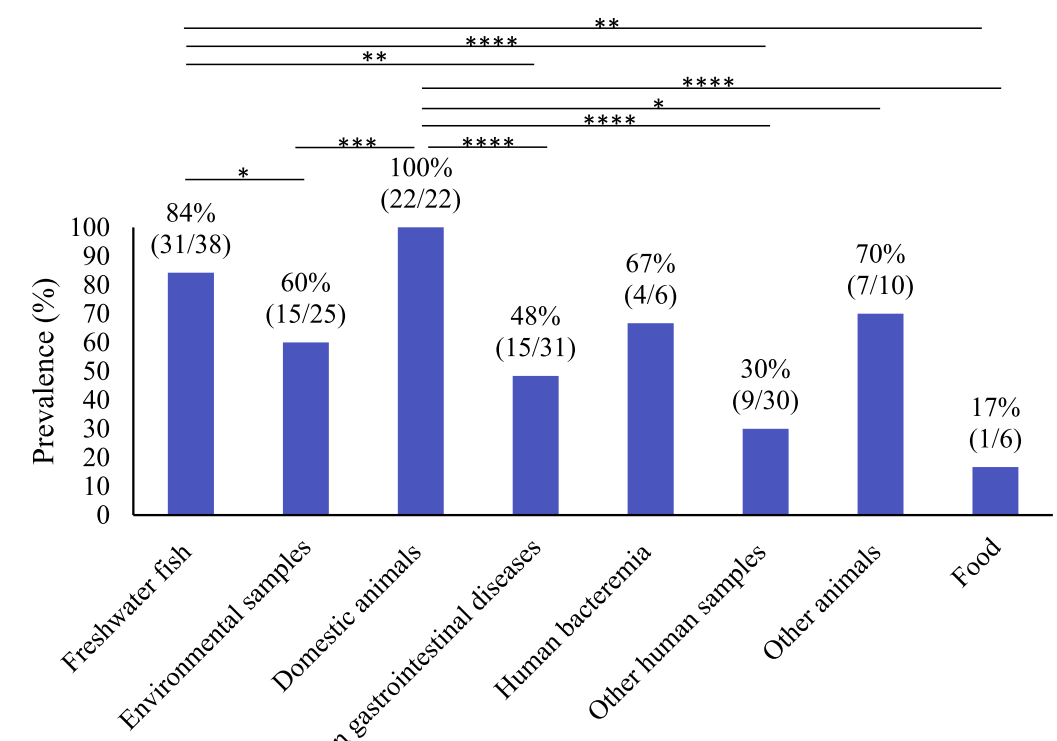

B

B FC951<smiles>C1CCC1</smiles>

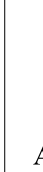

A29V

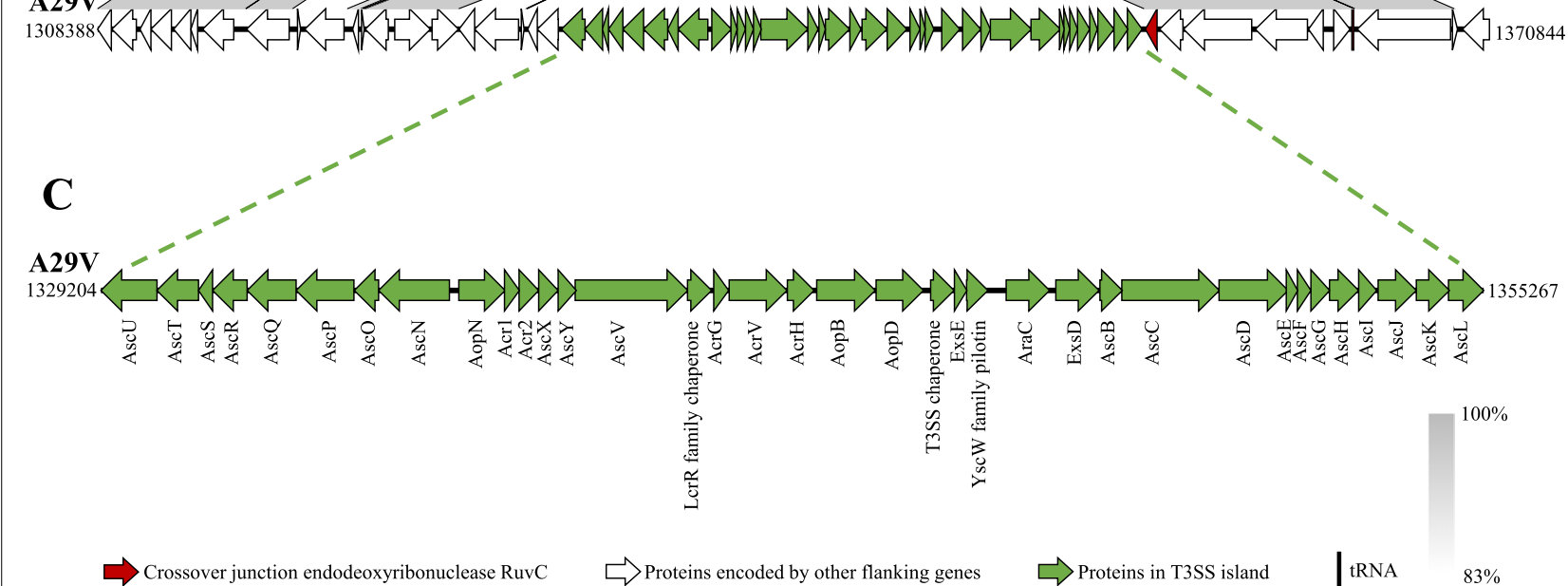

Fig. 2 The Aeromonas veronii genomic island AVI-1 containing the T3SS system. The AVI-1 genomic island identified in this study contains genes encoding T3SS, which is found in 106 of the 168 strains examined in this study. A The prevalence of T3SS in strains isolated from patients with gastrointestinal diseases was significantly lower than that in $A$. veronii strains isolated from freshwater fish $(p=0.0125)$ and domestic animals $(p<0.0001)$. B Comparison of the A. veronii genomes with T3SS (representative strain A29V) and without T3SS (representative strain FC951) shows that the AVI-1 genomic island is located adjacent to a gene encoding crossover junction endodeoxyribonuclease (red). The identical proteins in these two strains are shaded in grey. C Genes in the AVI-1 genomic island that encodes T3SS components. *Indicates statistical significance $\left({ }^{*} p<0.05 ;{ }^{* *} p<0.01 ;{ }^{* *} p<0.001 ;{ }^{* * *} p<0.0001\right)$. Other human samples include $A$. veronii strains isolated from sputum, wound infection, cholangiolithiasis bile and fecal samples of individuals without clinical information. Other animals include $A$. veronii strains isolated from mosquito gut, insect gut, Hirudo verbena digestive tract, grass carp, Heterelmis comalensis, Xiphophorus helleri, frog, snail, Andrias advidianus and alligator. The food group included strains isolated from various food 


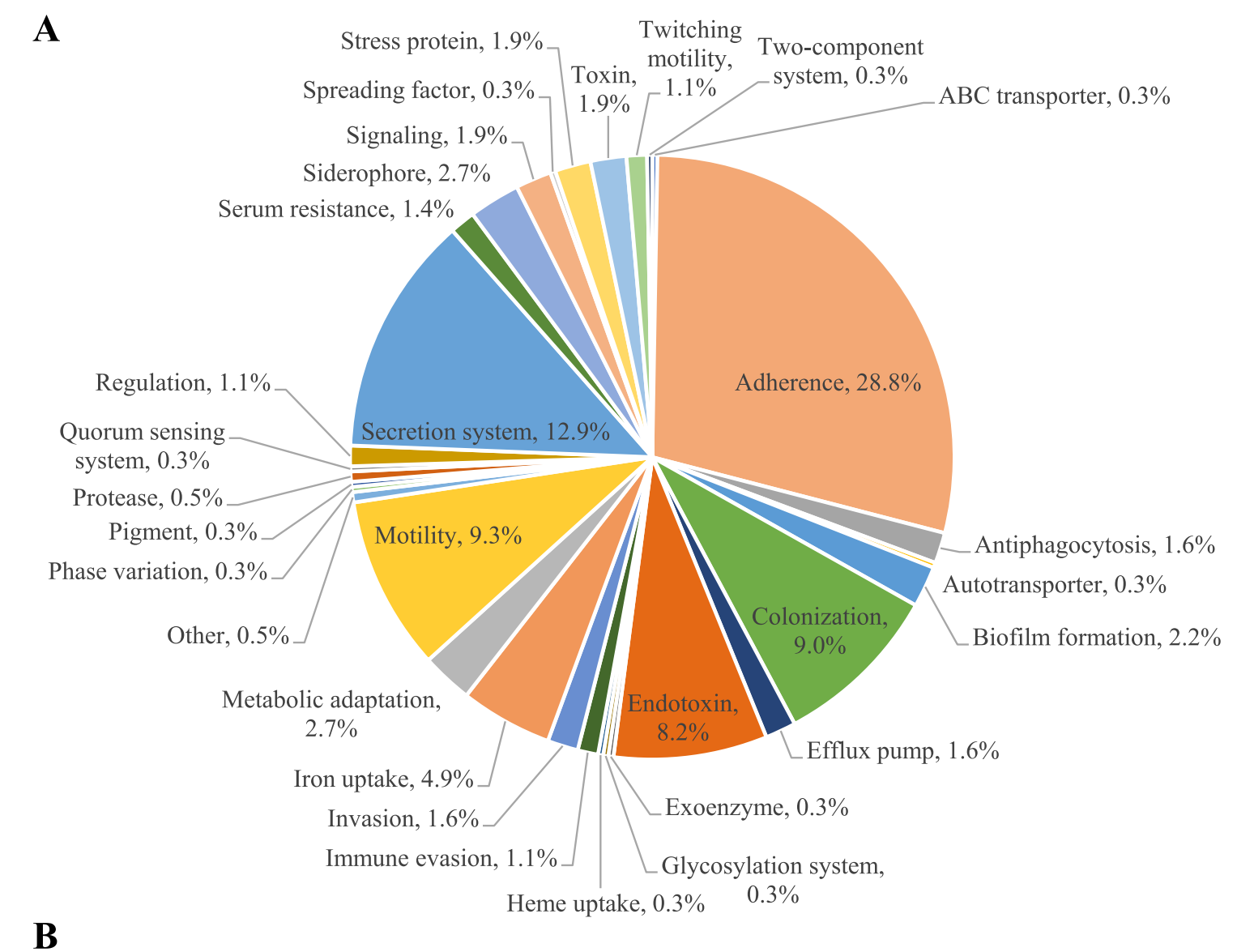

\begin{tabular}{|c|c|c|c|c|c|c|c|c|c|c|}
\hline Adherence & \multicolumn{10}{|c|}{$\begin{array}{l}\text { AHA } 1389 \text { cheA-2 cheB-2 cheR-3 cheV cheW cheW-2 cheY cheZ csgG flaA flab flaH flaJ fleN fleQ/flrC fleR/flrC } \\
\text { fleS/flrB flgA flgB flgC flgD flgE flgF flgG flgH flgI flgJ flgK flgL flgN flhA flhB flhF fliA fliE fliF fliG fliH fliI fliJ fliK } \\
\text { fliL fliM fliN flip fliR flmD flmH htpB IlpA kpsF Lap maf-1 maf-2 motA motX motY mshB mshC mshD mshE mshE } \\
\text { mshG mshH mshI mshI1 mshJ mshM mshN mshO mshQ nueA nueB pilR pomA2 pomB pomB2 tapB tapC tapF tapM } \\
\text { tapN tapO tapP tapQ tapT tapU tapV tapW tppC tppF tufa tufa VP1611 waaA waaF }\end{array}$} \\
\hline $\begin{array}{l}\text { Secretion } \\
\text { system }\end{array}$ & \multicolumn{10}{|c|}{$\begin{array}{l}\text { acr2 acrH acrR acrV aexT aopB aopD aopN ascB ascC ascD ascH ascJ ascK ascL ascN ascP ascQ ascR ascT ascU ascV } \\
\text { ascX ascY CBU_0270 CBU_0270 CBU_1566 exeA exeB exeC exeD exeE exeF exeG exeH exeI exeJ exeK exeL exeM } \\
\text { exeN exsA exsB exsC exsD lpg2936 tapD/pilD }\end{array}$} \\
\hline Motility & \multicolumn{10}{|c|}{$\begin{array}{l}\text { fleR fleR/flrC flgC flgE flgI flgJ fliF fliG fliP lafA lafB lafC lafE lafF lafK lafS lafT lafU lfgA lfgB lfgF lfgG lfgH lfgK } \\
\text { lfgL lfgN lfhA lfhB lfiH lfiI lfiM lfiN lfiR maf-5 }\end{array}$} \\
\hline Colonization & \multicolumn{10}{|c|}{$\begin{array}{l}\text { fleR/flrC flgC flgE flgI flgJ fliF fliG fliP lafA lafB lafC lafE lafF lafK lafS lafT lafU lfgA lfgB lfgF lfgG lfgH lfgK lfgL } \\
\text { lfgN lfhA lfhB lfiH lfiI lfiM lfiN lfiR maf-5 }\end{array}$} \\
\hline Endotoxin & \multicolumn{10}{|c|}{$\begin{array}{l}\text { bplF bplL galE galU gmhA/lpcA gtrB htrB kdsA kdsB lgtF lpxA lpxB lpxC lpxD lpxH lpxK msbA msbB opsX/rfaC rfaD } \\
\text { rfaE rffG waaA waaF waaQ wzt }\end{array}$} \\
\hline Iron uptake & \multicolumn{10}{|c|}{ ccmC ccmF chuW dhbC entA entB entE entF feoB fepA fepC hitC iraB iroN pvdE pvdH } \\
\hline $\begin{array}{l}\text { Metabolic } \\
\text { adaptation }\end{array}$ & \multicolumn{2}{|c|}{$\begin{array}{l}\text { bioA bioB carA carB ggt } \\
\text { hpt icl purCD purM pyrB }\end{array}$} & Siderophore & \multicolumn{2}{|c|}{$\begin{array}{l}\text { dhbC entA entB entE entF } \\
\text { fepA fepC iroN pvdE }\end{array}$} & \multicolumn{2}{|c|}{ Toxin } & \multicolumn{3}{|c|}{$\begin{array}{l}\text { aerA/act AHA_3217 } \\
\text { AHA_3493 cyaB hlyA zot }\end{array}$} \\
\hline \begin{tabular}{l|l} 
Biofilm & ad \\
formation & $\mathrm{m}$
\end{tabular} & \multicolumn{2}{|c|}{$\begin{array}{l}\text { adeG fleR/flrC mshE } \\
\mathrm{mshH} \text { pgaB pgaC }\end{array}$} & $\begin{array}{l}\text { Stress } \\
\text { protein }\end{array}$ & \multicolumn{2}{|c|}{$\begin{array}{l}\text { clpC clpE clpP katA katB } \\
\text { recN sodB }\end{array}$} & \multicolumn{2}{|c|}{ Antiphagocytosis } & \multicolumn{3}{|c|}{$\begin{array}{l}\text { algU algW cpsI mucD mucP } \\
\text { wcbT }\end{array}$} \\
\hline Efflux pump & \multicolumn{2}{|c|}{ acrA acrB farB mtrD } & Invasion & \multicolumn{2}{|c|}{ cheB invC/ilp lidL ompA } & \multicolumn{2}{|c|}{ Immune evasion } & \multicolumn{3}{|c|}{ glmU hasB rpe wbtL } \\
\hline Regulation & bfmR luxS relA & \multicolumn{2}{|c|}{ Serum resistance } & \multicolumn{2}{|c|}{ algU ompA wzt } & & & cheA eptC & \begin{tabular}{|l|l|} 
Protease \\
\end{tabular} & lasB stcE \\
\hline $\mathrm{ABC}$ transporter & \begin{tabular}{l|l|l} 
ter & hitC &
\end{tabular} & Autotra & & invC/ilp & & & EF0818 & Glycosy & ion system & \\
\hline Heme uptake & chuW & & $\mathrm{kpsF}$ & & & & \multicolumn{2}{|c|}{ Quorum sensing system } & \\
\hline Spreading factor & EF0818 & Signalli & & $\operatorname{cdpA}$ & Twitching moti & & pilR & & & \\
\hline
\end{tabular}

Fig. 3 Putative virulence factors in Aeromonas veronii strain A29V. Putative virulence factors in the complete genome of A. veronii strain A29V, a strain isolated from fecal sample of a patient with gastroenteritis, was identified through searches of the Virulence Factors Database. A total of 299 putative virulence was identified. A Percentages of virulence factors in different categories. B) Virulence genes in each virulence factor category 


\begin{tabular}{|c|c|c|c|c|c|c|}
\hline Strain & $\frac{5}{\frac{5}{2}}$ & 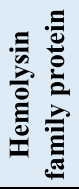 & 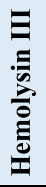 & 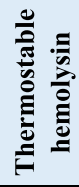 & 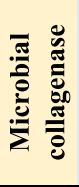 & $\stackrel{\vec{N}}{\circ}$ \\
\hline A20 & $\mathrm{P}$ & $\mathrm{P}$ & $\mathrm{P}$ & $P$ & $P$ & $\mathrm{~N}$ \\
\hline A20-10 & $\mathrm{P}$ & $\mathrm{P}$ & $P$ & $\mathrm{P}$ & $\mathrm{P}$ & $\mathrm{P}$ \\
\hline A20-12 & $\mathrm{P}$ & $\mathrm{P}$ & $\mathrm{P}$ & $\mathrm{P}$ & $\mathrm{P}$ & $\mathrm{P}$ \\
\hline A20-14 & $\mathrm{P}$ & P & $\mathrm{P}$ & $\mathrm{P}$ & $\mathrm{P}$ & $P$ \\
\hline A20-17 & $\mathrm{P}$ & $\mathrm{P}$ & $\mathrm{P}$ & $\mathrm{P}$ & $\mathrm{P}$ & $\mathrm{N}$ \\
\hline A20-5 & $\mathrm{P}$ & $\mathrm{P}$ & $\mathrm{P}$ & $\mathrm{P}$ & $\mathrm{P}$ & $\mathrm{N}$ \\
\hline A20-8 & P & P & $\mathrm{P}$ & $\mathrm{P}$ & $\mathrm{P}$ & $\mathrm{N}$ \\
\hline A21 & P & $\mathrm{P}$ & $\mathrm{P}$ & $\mathrm{P}$ & $\mathrm{P}$ & $\mathrm{N}$ \\
\hline A21-10 & $\mathrm{P}$ & $\mathrm{P}$ & $\mathrm{P}$ & $\mathrm{P}$ & $\mathrm{P}$ & $\mathrm{N}$ \\
\hline A21-11 & $\mathrm{P}$ & $\mathrm{P}$ & $\mathrm{P}$ & $\mathrm{P}$ & $\mathrm{P}$ & $\mathrm{N}$ \\
\hline A21-13 & $\mathrm{P}$ & $\mathrm{P}$ & $\mathrm{P}$ & $\mathrm{P}$ & $\mathrm{P}$ & $\mathrm{N}$ \\
\hline A21-14 & $\mathrm{P}$ & P & $\mathrm{P}$ & $\mathrm{P}$ & $\mathrm{P}$ & $\mathrm{N}$ \\
\hline A21-15 & $\mathrm{P}$ & $\mathrm{P}$ & $\mathrm{P}$ & $\mathrm{P}$ & $\mathrm{P}$ & $\mathrm{N}$ \\
\hline A21-16 & $\mathrm{P}$ & $\mathrm{P}$ & $\mathrm{P}$ & $\mathrm{P}$ & $\mathrm{P}$ & $\mathrm{N}$ \\
\hline A21-19 & $\mathrm{P}$ & $\mathrm{P}$ & $\mathrm{P}$ & $\mathrm{P}$ & $\mathrm{P}$ & $\mathrm{P}$ \\
\hline A21-4 & $\mathrm{P}$ & $\mathrm{P}$ & $\mathrm{P}$ & $\mathrm{P}$ & $\mathrm{P}$ & $\mathrm{P}$ \\
\hline A21-5 & $\mathrm{P}$ & $\mathrm{P}$ & $\mathrm{P}$ & $\mathrm{P}$ & $\mathrm{P}$ & $\mathrm{P}$ \\
\hline A21-6 & $\mathrm{P}$ & P & $\mathrm{P}$ & $P$ & $\mathrm{P}$ & $\mathrm{N}$ \\
\hline A21-8 & P & P & P & $\mathrm{P}$ & $\mathrm{P}$ & $\mathrm{P}$ \\
\hline A26 & $\mathrm{P}$ & $\mathrm{P}$ & $\mathrm{P}$ & $\mathrm{P}$ & $\mathrm{P}$ & $\mathrm{P}$ \\
\hline A27 & $\mathrm{P}$ & $\mathrm{P}$ & $\mathrm{P}$ & $\mathrm{P}$ & $\mathrm{P}$ & $\mathrm{P}$ \\
\hline A29V & $\mathrm{P}$ & $\mathrm{P}$ & $\mathrm{P}$ & $\mathrm{P}$ & $\mathrm{P}$ & $\mathrm{P}$ \\
\hline A7 & $\mathrm{P}$ & P & $\mathrm{P}$ & $\mathrm{P}$ & $\mathrm{P}$ & $\mathrm{N}$ \\
\hline A8 & $\mathrm{P}$ & $\mathrm{P}$ & $\mathrm{P}$ & $\mathrm{P}$ & $P$ & $\mathrm{~N}$ \\
\hline A9 & $\mathrm{P}$ & $\mathrm{P}$ & $\mathrm{P}$ & $\mathrm{P}$ & $\mathrm{P}$ & $\mathrm{N}$ \\
\hline BC88 & $\mathrm{P}$ & $\mathrm{P}$ & $\mathrm{P}$ & $\mathrm{P}$ & $\mathrm{P}$ & $\mathrm{N}$ \\
\hline FC951 & $\mathrm{P}$ & $\mathrm{P}$ & $\mathrm{P}$ & $\mathrm{P}$ & $\mathrm{P}$ & $\mathrm{N}$ \\
\hline $126-14$ & $\mathrm{P}$ & $\mathrm{P}$ & $\mathrm{P}$ & $\mathrm{P}$ & $\mathrm{P}$ & $\mathrm{N}$ \\
\hline $312 \mathrm{M}$ & $\mathrm{P}$ & $\mathrm{P}$ & $\mathrm{P}$ & $\mathrm{P}$ & $P$ & $\mathrm{~N}$ \\
\hline VBF557 & $P$ & $\mathrm{P}$ & $\mathrm{P}$ & $\mathrm{P}$ & $P$ & $P$ \\
\hline ERR1305902-bin.15 & $\mathrm{P}$ & $\mathrm{P}$ & $\mathrm{P}$ & $\mathrm{N}$ & $\mathrm{P}$ & $\mathrm{N}$ \\
\hline
\end{tabular}

Fig. 4 Prevalence of toxins in Aeromonas veronii strains isolated form fecal samples of patients with gastrointestinal diseases. Toxins identified in A. veronii strain A29V were further examined in other $A$. veronii strains by BLASTp. Conserved protein motifs were confirmed by pfam. Aerolysin and microbial collagenases (shaded in yellow) are secreted toxins

drinking water and fresh water [2-6]. Human Aeromonas gastrointestinal infections most often occur in warm weather $[1,10]$. Aeromonas species and their load in different types of drinking water and fresh water that is used for preparation of food should be monitored during different seasons, which will provide further information on the main sources that cause human Aeromonas gastrointestinal infections.

More than half of the 168 A. veronii strains (63.1\%) examined in this study had T3SS. T3SS is used by pathogenic bacteria to directly inject effector proteins into eukaryotic host cells, which facilitates bacterial infection of host cells or causes host cell apoptosis [23]. T3SS in A. veronii is located in the AVI-1 genomic island (Fig. 2). The AVI-1 genomic island is also present in the chromosome of A. hydrophila strains and plasmids in A. salmonicida, suggesting that $A$. veronii most likely has acquired T3SS via horizontal gene transfer from other Aeromonas species. An additional interesting finding from this study was that T3SS was significantly less present in A. veronii strains isolated from fecal samples of patients with gastrointestinal diseases as compared to strains isolated from freshwater fish and domestic animals (Fig. 2). This further supports the view that most of the $A$. veronii strains causing infections in human gastrointestinal tract were from a different source.

Nearly 300 putative virulence factors were identified in the complete genome of $A$. veronii strain A29V (Fig. 3). This shows that multiple virulence factors contribute to the pathogenesis of gastrointestinal diseases caused by $A$. veronii. We further examined toxins in the $31 \mathrm{~A}$. veronii strains isolated from patients with gastrointestinal diseases. Aerolysin, a secreted toxin, is a common virulence factor presenting in all $A$. veronii strains (Fig. 4). Aerolysin is a pore-forming toxin promoting osmotic lysis of host cells. Aerolysin in A. hydrophila was shown to perturb human intestinal epithelial tight junction integrity and cell lesion repair [24]. The second secreted toxin, microbial collagenase, was also found in all $31 \mathrm{~A}$. veronii strains isolated from patients with gastrointestinal diseases (Fig. 4). Bacterial collagenases degrade collagen in animal cell extracellular matrix and are important bacterial virulence factors. Microbial collagenase in A. veronii is involved in the pathogenesis of diseases caused by this bacterium in fish[25]. Its pathogenic role in human diseases requires further characterization. A previous study reported detection of Stx1 and Stx 2 toxin genes in some human Aeromonas isolates [25]. However, we did not find these toxin genes in any of the 31 strains isolated from patients with gastrointestinal diseases. Zot protein was found in $35.5 \%$ A. veronii strains. V. cholerae Zot protein damages intestinal epithelial barrier tight junctions and Campylobacter concisus Zot protein causes intestinal epithelial cell death [26, 27]. Multiple hemolysins in $A$. veronii were identified, which were demonstrated to be virulent to host cells in other bacterial species. The levels of toxins produced by different $A$. veronii strains remain to be further examined, which may contribute to their ability in causing human gastrointestinal diseases of different severity.

\section{Conclusions}

In summary, we report 25 genomes of $A$. veronii strains isolated from fecal samples of patients with gastrointestinal diseases, including one complete genome and 
24 draft genomes. Analysis of 168 global $A$. veronii genomes including those we have sequenced show that the global $A$. veronii strains formed three clusters and the majority of $A$. veronii strains from various sources were from a common ancestor. Most of the $A$. veronii strains isolated from patients with gastrointestinal diseases were closely related to each other, with only a small percentage of these strains were closely related to A. veronii strains isolated from freshwater fish, domestic animals or environmental samples. Nearly 300 putative virulence factors were identified. Aerolysin, microbial collagenase and multiple hemolysins were present in all strains isolated from patients with gastrointestinal diseases. Zot toxin was only present in some strains. T3SS in A. veronii was in the AVI-1 genomic island identified in this study, and most likely acquired via horizontal transfer from other Aeromonas species and was significantly less present in $A$. veronii strains isolated from patients with gastrointestinal diseases as compared to strains isolated from freshwater fish and domestic animals. These findings provide novel information on source of infection and virulence of $A$. veronii in human gastrointestinal diseases.

\section{Materials and methods}

\section{A. veronii genomes used in this study}

A total of 168 A. veronii genomes were analysed in this study, including 25 genomes sequenced in this study and 143 genomes publicly available. Currently, there are 156 A. veronii genomes available in the public databases, 13 genomes were excluded from this study due to lack of information on isolation hosts or country of isolation. The $25 \mathrm{~A}$. veronii strains sequenced in this study were isolated from fecal samples of patients with gastrointestinal diseases at the Douglass Hanly Moir Pathology laboratory in Sydney, Australia, during routine diagnostic procedure.

\section{Draft genome sequencing of $25 A$. veronii strains}

Sequencing and assembly of draft genomes of $25 \mathrm{~A}$. veronii strains were conducted as described in our previous study [28]. Briefly, bacterial DNA was extracted using Gentra Puregene Yeast/Bacteria Kit (Qiagen, Chadstone, Victoria, Australia). Briefly, the DNA libraries were sequenced via the 150 bp or 250 bp paired-end sequencing chemistry on the MiSeq Personal Sequencer [29]. Reads were assembled using Shovill (v 1.0.5), and genome coverage was calculated using qualimap ( $v$ 2.2.1) [30]. Sequencing of the draft genome was performed in the Marshall Centre for Infectious Diseases Research at the University of Western Australia.

\section{Complete genome sequencing of $A$. veronii strain A29V}

A. veronii strain $\mathrm{A} 29 \mathrm{~V}$ was also subjected to genome sequencing using Oxford Nanopore sequencing technique. Bacterial DNA used for this part of genome sequencing was extracted with phenol-chloroform. Libraries were prepared using the Native Barcoding Expansion kit (EXP-NBD104, Nanopore) and the Ligation Sequencing Kit (SQK-LSK109, Nanopore). The libraries were then loaded onto a R9.4 flow cell (FLOMIN106) and sequenced on the GridION sequencing device (Nanopore). The nanopore sequencing of A. veronii strain A29V genome was performed at the Ramaciotti Centre for Genomics at the University of New South Wales. Basecalling were performed using Guppy (v 4.0.14). Statistics of the reads were generated using Nanostat (v 1.5.0) and genome coverage was estimated using Minimap2 (v 2.17) and qualimap (v 2.2.1) [30].

To obtain the complete genome of $A$. veronii strain $\mathrm{A} 29 \mathrm{~V}$, the reads of $A$. veronii generated by nanopore and Illumina MiSeq were used for hybrid assembly using Unicycler (v 0.4.7). The details of hybrid assembly were described in our previous study [31].

\section{Annotation of the $A$. veronii genomes sequenced in this study}

The complete genome of $A$. veronii strain A29V and 24 draft $A$. veronii genomes sequenced in this study were annotated using the NCBI Prokaryotic Genome Annotation Pipeline, Rapid Annotation using Subsystem Technology, and Prokka (v 1.14.5) [32-34].

\section{Phylogenetic analysis}

Core genome was generated using Roary (v3.12.0) [35]. The maximum likelihood phylogenetic tree based on core genome was generated using FastTree (v 2.1.11) [36]. The ANI values of each $A$. veronii genome against the genomes remaining $167 A$. veronii strains were calculated using FastANI (v 1.32) [37].

\section{Secretion systems}

Secretion systems were examined in the genomes of 168 A. veronii strains. Prokka annotated protein files of the 168 A. veronii strains were submitted to MacSyFinder, all available protein secretion systems were searched using the default settings [38]. Visualisation of T3SS was generated using EasyFig [39]. The nucleotide sequences of A. veronii T3SS were searched against the genomes of all bacterial strains in NCBI non-redundant nucleotide database using BLASTn [40]. 
Identification of $A$. veronii strains that were closely related to $A$. veronii strains isolated from fecal samples of patients with gastrointestinal diseases

In this study, $31 \mathrm{~A}$. veronii strains that were isolated from fecal samples of patients with gastrointestinal diseases, including the $25 \mathrm{~A}$. veronii strains that we have sequenced and additional six $A$. veronii strains in the public databases. The six $A$. veronii strains from public databases were strain ERR1305902-bin.15 from Denmark, strain 126-14 from China, two strains (FC951 and VBF557) from India, strain $312 \mathrm{M}$ from Brazil, and a previously reported strain (BC88) from Australia.

Among the 168 A.veronii strains, the strain that had the highest ANI value against each of the $31 \mathrm{~A}$. veronii strains isolated from fecal samples of patients with gastrointestinal diseases was identified as the most closely related strain.

\section{Putative virulence factor in $A$. veronii strains isolated from patients with gastrointestinal diseases}

Putative virulence factors in the complete genome of $A$. veronii strain isolated from a patient with gastroenteritis that was sequenced in this study were firstly identified through searches of the Virulence Factors Database (VFDB) $[17,41]$. The presence of toxins in the $31 \mathrm{~A}$. veronii strains isolated from patients with gastrointestinal diseases was then searched using BLASTp, and conserved protein motifs were confirmed using pfam [40, 42].

\section{Statistical analysis}

Fisher's exact test (two-tailed) was used for analysis of the presence of T3SS in A. veronii strains isolated from different sources. $p<0.05$ was considered to be statistically significant. Statistical analysis was performed using GraphPad Prism 7.

\section{Supplementary Information}

The online version contains supplementary material available at https://doi. org/10.1186/s12864-022-08402-1.

\section{Additional file 1.}

Additional file 2.

Acknowledgements

Not applicable.

\section{Authors' contribution}

$\mathrm{FL}$ and $\mathrm{CY}$ : prepared bacterial DNA for sequencing and analysed the genome data. ACYT: sequenced the draft genomes. LZ, MCW and SMR: conceived the project. FL, LZ and CY: played a major role in writing the manuscript. MCW: provided the A. veronii strains sequenced in this study. ACYT, MCW and SMR: provided critical feedback and helped in editing the manuscript. The author(s) read and approved the final manuscript.

\section{Funding}

This work is supported by a Faculty Research Grant awarded to LZ from the University of New South Wales (grant number PS46772)

\section{Availability of data and materials}

Genome assemblies and raw data of $25 \mathrm{~A}$. veronii genomes sequenced in this study (one complete and 24 draft genomes) have been deposited in NCBI bacterial genome database and Sequence Read Archive database respectively. The accession numbers for the genome assemblies and raw data are available in Table 1.

\section{Declarations}

Ethics approval and consent to participate

Not applicable.

\section{Consent for publication}

Not applicable.

\section{Competing interests}

The authors declare that they have no competing interests.

\section{Author details}

${ }^{1}$ School of Biotechnology and Biomolecular Sciences, University of New South Wales, Sydney, NSW 2052, Australia. ${ }^{2}$ Helicobacter Research Laboratory, School of Pathology and Laboratory Medicine, Marshall Centre for Infectious Diseases Research and Training, University of Western Australia, Perth, Australia. ${ }^{3}$ Douglass Hanly Moir Pathology, 14 Giffnock Ave, Macquarie Park, NSW 2113, Australia. ${ }^{4}$ Gastrointestinal and Liver Unit, Prince of Wales Hospital, University of New South Wales, Sydney, Australia.

Received: 6 September 2021 Accepted: 16 February 2022

Published online: 28 February 2022

\section{References}

1. Fernández-Bravo A, Figueras MJ. An Update on the Genus Aeromonas: Taxonomy, Epidemiology, and Pathogenicity. Microorganisms. 2020;8(1):129.

2. Burke V, Robinson J, Gracey M, Peterson D, Partridge K. Isolation of Aeromonas hydrophila from a metropolitan water supply: seasonal correlation with clinical isolates. Appl Environ Microbiol. 1984;48(2):361-6.

3. Kivanc M, Yilmaz M, Demir F. The occurrence of Aeromonas in drinking water, tap water and the porsuk river. Braz J Microbiol. 2011;42(1):126-31.

4. van Bel N, van der Wielen P, Wullings B, van Rijn J, van der Mark E, Ketelaars $\mathrm{H}$, et al. Aeromonas Species from Nonchlorinated Distribution Systems and Their Competitive Planktonic Growth in Drinking Water. Appl Environ Microbiol. 2020;87(5):e02867-e2920.

5. Egorov Al, Best JMB, Frebis CP, Karapondo MS. Occurrence of Aeromonas spp. in a random sample of drinking water distribution systems in the USA. J Water Health. 2011;9(4):785-98.

6. Pianetti A, Falcioni T, Bruscolini F, Sabatini L, Sisti E, Papa S. Determination of the Viability of Aeromonas hydrophila in Different Types of Water by Flow Cytometry, and Comparison with Classical Methods. Appl Environ Microbiol. 2005;71(12):7948-54.

7. Chen F, Sun J, Han Z, Yang X, Xian J-a, Lv A, et al. Isolation, Identification and Characteristics of Aeromonas veronii From Diseased Crucian Carp (Carassius auratus gibelio). Front Microbiol. 2019;10(2742):2742.

8. Wang B, Mao C, Feng J, Li Y, Hu J, Jiang B, et al. A First Report of Aeromonas veronii Infection of the Sea Bass, Lateolabrax maculatus in China. Front Vet Sci. 2021;7(1220):1220.

9. Baumgartner WA, Ford L, Hanson L. Lesions caused by virulent Aeromonas hydrophila in farmed catfish (Ictalurus punctatus and I. punctatus $\times I$. furcatus) in Mississippi. J Vet Diagn Invest. 2017;29(5):747-51.

10. Yuwono C, Wehrhahn MC, Liu F, Riordan SM, Zhang L. The Isolation of Aeromonas Species and Other Common Enteric Bacterial Pathogens from 
Patients with Gastroenteritis in an Australian Population. Microorganisms. 2021;9(7):1440.

11. Zhou Y, Yu L, Nan Z, Zhang P, Kan B, Yan D, et al. Taxonomy, virulence genes and antimicrobial resistance of Aeromonas isolated from extraintestinal and intestinal infections. BMC Infect Dis. 2019;19(1):158.

12. Sedláček I, Krejčí E, Andělová A, Sedláčková M, Porazilová I, Holochová P. Aeromonas hydrophila subsp. dhakensis - a causative agent of gastroenteritis imported into the Czech Republic. Ann Agric Environ Med. 2012;19(3):409-13.

13. Senderovich Y, Ken-Dror S, Vainblat I, Blau D, Izhaki I, Halpern M. A molecular study on the prevalence and virulence potential of Aeromonas spp. recovered from patients suffering from diarrhea in Israel. PLoS One. 2012; 7(2):e30070.

14. Chen PL, Tsai PJ, Chen CS, Lu YC, Chen HM, Lee NY, et al. Aeromonas stool isolates from individuals with or without diarrhea in southern Taiwan: Predominance of Aeromonas veronii. J Microbiol Immunol Infect. 2015;48(6):618-24.

15. Wu CJ, Ko WC, Lee NY, Su SL, Li CW, Li MC, et al. Aeromonas Isolates from Fish and Patients in Tainan City, Taiwan: Genotypic and Phenotypic Characteristics. Appl Environ Microbiol. 2019:85(21):e01360-e1419.

16. Lobatón T, Hoffman I, Vermeire S, Ferrante M, Verhaegen J, Van Assche G. Aeromonas Species: An Opportunistic Enteropathogen in Patients with Inflammatory Bowel Diseases? A Single Center Cohort Study. Inflamm Bowel Dis. 2015;21(1):71-8.

17. Tekedar HC, Kumru S, Blom J, Perkins AD, Griffin MJ, Abdelhamed H, et al. Comparative genomics of Aeromonas veronii: Identification of a pathotype impacting aquaculture globally. PLoS One. 2019;14(8):e0221018.

18. Li Y, Liu Y, Zhou Z, Huang H, Ren Y, Zhang Y, et al. Complete genome sequence of Aeromonas veronii strain B565. J Bacteriol. 2011;193(13):3389-90.

19. Roger F, Marchandin H, Jumas-Bilak E, Kodjo A, col BVHsg, Lamy B. Multilocus genetics to reconstruct aeromonad evolution. BMC Microbiol. 2012;12:62.

20. Hughes Heather Y, Conlan Sean P, Lau Anna F, Dekker John P, Michelin Angela V, Youn J-H, et al. Detection and Whole-Genome Sequencing of Carbapenemase-Producing Aeromonas hydrophila Isolates from Routine Perirectal Surveillance Culture. J Clin Microbiol. 2016;54(4):1167-70.

21. Ghatak S, Blom J, Das S, Sanjukta R, Puro K-u, Mawlong M, et al. Pangenome analysis of Aeromonas hydrophila, Aeromonas veronii and Aeromonas caviae indicates phylogenomic diversity and greater pathogenic potential for Aeromonas hydrophila. Antonie van Leeuwenhoek. 2016:109:945-56

22. Hatrongjit R, Kerdsin A, Takeuchi D, Wongsurawat T, Jenjaroenpun P, Chopjitt P, et al. Genomic Analysis of Aeromonas veronii C198, a Novel Mcr-3.41-Harboring Isolate from a Patient with Septicemia in Thailand. Pathogens. 2020;9(12):1031.

23. Wagner S, Grin I, Malmsheimer S, Singh N, Torres-Vargas CE, Westerhausen $\mathrm{S}$. Bacterial type III secretion systems: a complex device for the delivery of bacterial effector proteins into eukaryotic host cells. FEMS Microbiol Lett. 2018;365(19):fny201.

24. Bücker R, Krug SM, Rosenthal R, Günzel D, Fromm A, Zeitz M, et al. Aerolysin From Aeromonas hydrophila Perturbs Tight Junction Integrity and Cell Lesion Repair in Intestinal Epithelial HT-29/B6 Cells. J Infect Dis. 2011;204(8):1283-92.

25. Han H-J, Taki T, Kondo H, Hirono I, Aoki T. Pathogenic potential of a collagenase gene from Aeromonas veronii. Can J Microbiol. 2007;54(1):1-10

26. Fasano A, Baudry B, Pumplin DW, Wasserman SS, Tall BD, Ketley JM, et al. Vibrio cholerae produces a second enterotoxin, which affects intestinal tight junctions. PNAS. 1991;88(12):5242-6.

27. Mahendran V, Liu F, Riordan SM, Grimm MC, Tanaka MM, Zhang L. Examination of the effects of Campylobacter concisus zonula occludens toxin on intestinal epithelial cells and macrophages. Gut Pathog. 2016;8(1):18

28. Liu F, Ma R, Tay CYA, Octavia S, Lan R, Chung HKL, et al. Genomic analysis of oral Campylobacter concisus strains identified a potential bacterial molecular marker associated with active Crohn's disease. Emerg Microbes Infect. 2018;7(1):64.

29. Chung HKL, Tay A, Octavia S, Chen J, Liu F, Ma R, et al. Genome analysis of Campylobacter concisus strains from patients with inflammatory bowel disease and gastroenteritis provides new insights into pathogenicity. Sci Rep. 2016;6(1):1-14.
30. García-Alcalde F, Okonechnikov K, Carbonell J, Cruz LM, Götz S, Tarazona $S$, et al. Qualimap: evaluating next-generation sequencing alignment data. Bioinformatics. 2012;28(20):2678-9.

31. Liu F, Chen S, Luu LDW, Lee SA, Tay ACY, Wu R, et al. Analysis of complete Campylobacter concisus genomes identifies genomospecies features, secretion systems and novel plasmids and their association with severe ulcerative colitis. Microb Genom. 2020;6(11):mgen000457.

32. Tatusova T, DiCuccio M, Badretdin A, Chetvernin V, Nawrocki EP, Zaslavsky $L$, et al. NCBI prokaryotic genome annotation pipeline. Nucleic Acids Res. 2016;44(14):6614-24.

33. Aziz RK, Bartels D, Best AA, DeJongh M, Disz T, Edwards RA, et al. The RAST Server: Rapid Annotations using Subsystems Technology. BMC Genomics. 2008:9(1):75.

34. Seemann T. Prokka: rapid prokaryotic genome annotation. Bioinformatics. 2014;30(14):2068-9.

35. Page AJ, Cummins CA, Hunt M, Wong VK, Reuter S, Holden MT, et al. Roary: rapid large-scale prokaryote pan genome analysis. Bioinformatics. 2015;31(22):3691-3.

36. Price MN, Dehal PS, Arkin AP. FastTree: computing large minimum evolution trees with profiles instead of a distance matrix. Mol Biol Evol. 2009;26(7):1641-50.

37. Jain C, Rodriguez-R LM, Phillippy AM, Konstantinidis KT, Aluru S. High throughput ANI analysis of 90K prokaryotic genomes reveals clear species boundaries. Nat Commun. 2018;9(1):1-8.

38. Abby SS, Cury J, Guglielmini J, Néron B, Touchon M, Rocha EPC. Identification of protein secretion systems in bacterial genomes. Sci Rep. 2016;6:23080

39. Sullivan MJ, Petty NK, Beatson SA. Easyfig: a genome comparison visualizer. Bioinformatics. 2011;27(7):1009-10.

40. Johnson M, Zaretskaya I, Raytselis Y, Merezhuk Y, McGinnis S. Madden TL NCBI BLAST: a better web interface. Nucleic Acids Res. 2008;36(suppl_2):W5-9.

41. Chen L, Yang J, Yu J, Yao Z, Sun L, Shen Y, et al. VFDB: a reference database for bacterial virulence factors. Nucleic Acids Res. 2005;33:D325-8 (Database issue).

42. Bateman A, Coin L, Durbin R, Finn RD, Hollich V, Griffiths-Jones $S$, et al. The Pfam protein families database. Nucleic Acids Res. 2004;32(suppl_1):D138-41.

\section{Publisher's Note}

Springer Nature remains neutral with regard to jurisdictional claims in published maps and institutional affiliations.

Ready to submit your research? Choose BMC and benefit from:

- fast, convenient online submission

- thorough peer review by experienced researchers in your field

- rapid publication on acceptance

- support for research data, including large and complex data types

- gold Open Access which fosters wider collaboration and increased citations

- maximum visibility for your research: over $100 \mathrm{M}$ website views per year

At BMC, research is always in progress.

Learn more biomedcentral.com/submissions 